\title{
Estado, educación \\ e intervención psicopedagógica en la Ciudad de México en la primera mitad del siglo $\mathrm{XX}^{1}$ \\ State, Education and Psycho-Pedagogical Intervention in Mexico City during the First Half of the Twentieth Century
}

\author{
Antonio Padilla Arroyo \\ Universidad Autónoma del Estado de Morelos \\ apadilla@buzon.uaem.mx \\ antonin_19@yahoo.com.mx
}

\begin{abstract}
Resumen
Este texto tiene el objetivo principal de identificar y examinar algunas de las razones por las cuales se transitó de lo que puede definirse como una "revolución antropológica", que pretendía impulsar una profunda transformación en todos los órdenes de la vida del país, al diseño de una estrategia de intervención psicopedagógica, lo cual significó delimitar un campo de estudio e intervención con el fin de garantizar el orden y control de amplios grupos de la sociedad mexicana por parte de las elites en el transcurso de la primera mitad del siglo XX. De esta manera, es posible reconocer líneas de ruptura y continuidad entre el antiguo régimen y el Estado posrevolucionario mexicano, en particular el compromiso social que surgió del pacto que representó el movimiento armado de 1910-1920 en relación con los mecanismos de control educativo y social.
\end{abstract}

Palabras clave: Estado, intervención psicopedagógica, instituciones de educación correctiva.

\begin{abstract}
This article identifies and examines the reasons for a transition in Mexican national policies from an 'anthropological revolution', which sought the deep transformation of the country, to a new strategy

\footnotetext{
${ }^{1}$ Este texto forma parte de una investigación más amplia titulada Representaciones, actores, prácticas e instituciones en la educación especial en México, 1890-2005, la cual cuenta con el apoyo financiero del Consejo Nacional de Ciencia y Tecnología (Conacyt), de México.
} 
based on psycho-pedagogical intervention. The latter brought the definition of an expert field of study and intervention which sought to guarantee the control and order of certain social groups by an elite during the first half of the twentieth century. Continuity and change between the Ancien Régime and the postrevolutionary state are analysed, and special emphasis is given to the impact of the political pact emerging from the 1910-1920 armed revolution, and its social commitment, on social and educational control.

Keywords: State, Psycho-Pedagogical Intervention, Correctional Schools

\section{Introducción}

En México, después del movimiento armado revolucionario de 1910-1920, uno de los principales objetivos de las elites intelectuales y políticas fue incorporar a amplios sectores de la población a lo que se definía como el desarrollo y la cultura nacionales. Como parte del proceso de construcción del nuevo orden posrevolucionario, se diseñaron una serie de estrategias dirigidas a atender las condiciones políticas, económicas, sociales y culturales que se resumían en una profunda crisis en todos los órdenes de la vida del país. Para esto se trazó un ambicioso proyecto, cuyo objetivo central era la formación de un "nuevo hombre" y, por añadidura, de un nuevo "ser nacional". Con éste sería posible resolver la grave y dolorosa realidad legada por el régimen porfirista y las secuelas del movimiento armado.

El proyecto consistió en trazar una política cultural y social para transformar los modos de vida que prevalecían en la sociedad mexicana, en particular en grupos sociales, en tanto que se juzgaba que estos eran fuente de ideas, valores, comportamientos y actitudes nocivas, antisociales, amorales y, en última instancia, criminales, lo que obstaculizaba forjar la identidad y la cultura nacionales.

Asimismo, el proyecto contenía una serie de acciones eugenésicas que impidieran o limitaran la reproducción social y biológica de esos grupos en tanto que se consideraban uno de los factores esenciales de la "degeneración" de la sociedad mexicana. De acuerdo con Beatriz Urías Horcasitas, en las décadas de 1920 a 1940 se delineó y delimitó un programa de "ingeniería social" que se sustentaba en dos vertientes. La primera, una revolución cultural que pretendía transformar la mentalidad de los individuos por medio de la elevación de su nivel educativo y sustituir las creencias religiosas por valores laicos con orientación patriótica y familiar. Una de las expresiones nítidas fue la escuela rural, la cual sería el eje de la gran mutación social y cultural (Vaughan, 2001: 26-27; 52-53). ${ }^{2}$ La segunda, una "revolución

\footnotetext{
2 Vaughan pone en duda que las tesis del darwinismo social hayan sido compartidas por "los educadores revolucionarios mexicanos" y, por lo tanto, del diseño de una ingeniería social. Es posible que esos educadores no las compartieran, aunque es evidente que comunidades científicas sí las incorporaron como parte del bagaje conceptual
} 
antropológica", cuyo pilar era el mestizaje y la erradicación de la herencia degenerada que operaba en todo el tejido social, según sus promotores. Este programa, en términos muy similares a lo que acontecía en el pensamiento social en Europa, retomó y amalgamó las ideas sobre las razas que se gestaron durante el siglo XIX, con elementos de la eugenesia y de la higiene mental. Para ello, se recuperaron tesis que sostenían diversas disciplinas e incipientes "comunidades científicas", que en conjunto configuraron un bloque que contribuyó a la formación de una "ideología de la depuración racial". Ambas revoluciones implicaban apuntalar una nueva relación política entre gobernantes y gobernados, que se basaría en la organización corporativa de las clases obrera y campesina y que fortalecería un nuevo nacionalismo y, por ende, al régimen político que lo encarnaba ${ }^{3}$ (Urías, 2007: 12-13; Stern, 2002: 294-295).

A este respecto, Urías disecciona ese bloque ideológico en los siguientes términos:

Los antropólogos cercanos a la esfera del poder promovieron una política indigenista de unidad racial. La sociología criminal, influida por las premisas de la teoría jurídica de la "defensa social", hizo propuestas concretas para atajar la criminalidad considerando que se trataba de una tendencia innata en determinados individuos y grupos étnicos. Las políticas demográficas encararon el problema de la despoblación del país promoviendo la inmigración de individuos de raza blanca. Finalmente, los médicos y psiquiatras que adoptaron los supuestos de la eugenesia y la higiene mental establecieron un conjunto de medidas para controlar la reproducción de "indeseables", entre los que quedaron incluidos los alcohólicos, los toxicómanos, los epilépticos, los enfermos mentales, los individuos aquejados de enfermedades venéreas o de desviaciones sexuales (Urías, 2007: 12-13).

El inicial impulso transformador de las elites fue modificándose hasta reducirse a una estrategia de intervención psicopedagógica. De esta manera, se pretende responder a las siguientes preguntas: ¿Cuáles fueron las razones que explican la formulación de una política de intervención psicopedagógica? ¿Cuáles cambios conllevó este tránsito? ¿Cuáles fueron los

y metodológico que guiaba sus investigaciones y explicaciones acerca de las desviaciones y anormalidades sociales y mentales que padecían grupos e individuos. Habría que preguntarse, en todo caso, si las comunidades científicas estaban más atentas y preocupadas por el mundo urbano más que por el mundo rural, además de que este rechazo se fue debilitando a la par que el impulso justiciero que dominaba la educación rural en las décadas de 1920 y 1930 (Vaughan, 2001; 53-55).

${ }^{3}$ Tanto Alexandra Stern como Beatriz Urías sostienen posturas muy similares acerca de las disciplinas que sustentaban la teoría eugenésica y la influencia del herederismo en ésta: la psicología, la genética y la bacteriología. Los eugenistas mexicanos promovieron sus postulados para explicar tres elementos claves dentro de las prácticas culturales: sexualidad, maternidad e infancia. Estos ámbitos se consideraban primordiales en reproducción y la socialización de los ciudadanos y, por ende, en la construcción del Estado mexicano y en el rediseño de la nación mexicana (Urías, 2007: 12-13; Stern, 2002: 294-295) 
desplazamientos en las representaciones y, por añadidura, en la conformación de las comunidades científicas? ${ }^{4}$

En estas mutaciones es posible identificar líneas de ruptura y continuidad entre el antiguo régimen y el Estado posrevolucionario mexicano, en particular entre la décadas de 1920 a 1940.

\section{Estado mexicano y "revolución antropológica"}

En las dos décadas siguientes que sucedieron a la fase más violenta de la revolución mexicana se fundaron o se reorganizaron un conjunto de instituciones de atención y protección social, incluidas las educativas, que se orientaron a mitigar los efectos más nocivos del movimiento revolucionario en distintas zonas del país, entre los que pueden mencionarse las epidemias que asolaron a amplias regiones del territorio nacional, la desorganización de las familias y de los grupos sociales y las fracciones políticas o las circunstancias de abandono u orfandad en la que quedaron hombres y mujeres, niños y niñas, a consecuencia de los enfrentamientos armados y de los movimientos y los desplazamientos geográficos en la búsqueda de zonas de mayor seguridad. ${ }^{5}$

Vale recordar que la situación social, económica y política en la que se encontraba el país fue especialmente delicada en el periodo de estudio, derivada del movimiento armado se agravó a causa de la gran depresión de finales de la década de los años de 1920. Tales factores forzaron a establecer alianzas políticas entre los diferentes grupos políticos para mejorar las condiciones de vida de amplios sectores de la sociedad mexicana, lo cual obligó a reflexionar en torno al significado y la naturaleza del Estado mexicano (Werner, 1994: 483495; Meyer, 1999: 257 y ss). Al mismo tiempo, como intento ilustrar, el periodo en que se sitúa el trabajo fue definitorio no sólo para trazar los nuevos perfiles institucionales, sino para

\footnotetext{
${ }^{4}$ Cabe destacar que en los últimos años ha habido un interés renovado por examinar la constitución de las disciplinas y las comunidades científicas, así como su influencia y sus relaciones entre el poder científico y el poder político, las cuales fueron especialmente importantes en la época de estudio. Alberto del Castillo señala que la conformación de estas comunidades y disciplinas científicas se fortaleció durante el periodo conocido como porfiriato (18761910-1911), lo cual se tradujo en un interés creciente por la infancia y la consolidación de instituciones de asistencia a la niñez, aunque no sólo por ella (Del Castillo, 2006: 70 y ss). Estas comunidades desempeñarían un papel fundamental en la comprensión y en el diseño del programa de "ingeniería social" concebida por las elites políticas y culturales.

${ }^{5}$ Según cálculos de Werner, la población se redujo, entre 1910 y 1921, en 360 mil personas, esto es, pasó de 15.16 a 14.8 millones de habitantes debido a factores relacionados con el movimiento armado: emigración, enfermedades epidémicas y desnutrición (Werner, 1994: 528). De acuerdo con Marcial Avendaño, en el Distrito Federal la población urbana aumentó entre 1910 y 1921 del 11.7\% al 14\%, en números absolutos de 721 mil a 906 mil habitantes. Atribuye tal incremento a que miles de personas emigraron en busca de refugio y alimento en los años de mayor violencia social y política, lo que provocó hacinamiento y precarias condiciones de higiene (Marcial, 2004: 334). También puede consultarse (Aguilar y Meyer, 2008: 87-89; 123-125).
} 
consolidar un saber que involucraba diversas disciplinas científicas y escolares y que había tenido sus primeros desarrollos en el siglo XIX, el cual tenía como centro de interés el estudio de la infancia y la familia (Padilla, 2009).

En este sentido, una de las tareas más ingentes fue garantizar la protección a la infancia y, por extensión, a la familia, por medio de iniciativas legales e institucionales. Con esta intención se promovieron una serie de reuniones de especialistas, así como de otros grupos y asociaciones sociales que, entre otras cosas, pretendían reformar y fundar instituciones cuya tarea primordial era procurar seguridad y asistencia (Padilla, 2008; Tiana, 2005).

Así, uno de los productos de sus cavilaciones fue un saber en torno a la infancia en general y la niñez anormal y delincuente, en particular, porque consideraba que este sector se hallaba en una situación social, educativa, económica y cultural precaria. Especialistas, reformadores y autoridades políticas coincidieron en que ésta era la expresión más evidente de lo que había que atender y resolver tanto por la política cultural como por la política eugenésica. De igual modo, sus reflexiones incluyeron a las instituciones que se ocuparían de brindar atención y salvaguarda hacia esos sectores. Una hipótesis que aquí se sostiene es que en la medida en que se avanzó en el conocimiento acerca de la infancia, se diseñaron o se adaptaron instrumentos para la obtención de información empírica y se privilegiaron ciertos saberes y ciertas comunidades científicas. Ya no se aspiró a una revolución antropológica que involucrara al conjunto de la sociedad mexicana, sino a modificar hábitos de grupos específicos y, dentro de estos, a ciertos individuos y grupos sociales por medio de una intervención especializada, en específico de campesinos, indígenas y pobres urbanos. ${ }^{6}$ Dicha intervención comprendió diversas facetas y acciones de las dependencias estatales tanto en el plano nacional como estatal o local. En 1922, el Departamento de Salubridad Pública emprendió campañas de propaganda y educación higiénicas que tenían el objetivo de persuadir a los habitantes del campo y la ciudad acerca de las ventajas que acompañaban la conservación de la salud asociándolas al bienestar de la patria y la formación de los ciudadanos. De hecho, el Estado mexicano vinculó, en gran medida, la inculcación y la modificación de los hábitos higiénicos a determinadas prácticas culturales. Las autoridades educativas y sanitarias consideraron que la indumentaria servía para identificar a los grupos sociales y raciales. Por ejemplo, el uso del pantalón se asociaba a los mestizos, con lo cual se acercaban al estilo de vida occidental, mientras que el calzón a los indígenas, lo que constituía un signo de atraso e incivilidad. La escuela fue un medio primordial para la promoción de la higiene, en particular, como de la

\footnotetext{
${ }^{6}$ Por otra parte, el concepto de intervención psicopedagógica alude a la estrategia para la utilización de los saberes que permitan fijar los objetivos, los problemas a resolver, los cuales implican su análisis a profundidad, realizar las evaluaciones precisas del carácter, la magnitud y las posibilidades de los distintos elementos de que se dispone y las líneas de acción de los distintos instancias y poderes para desarrollar las estrategias. (Yarza, Alexander y Lorena Rodríguez, 2007: 11-116).
} 
imposición de prácticas culturales en general. Si bien las autoridades no promovieron medidas expresas para propiciar nuevas formas de vestir, los maestros parecen haber desempeñado un papel fundamental en el abandono paulatino de cierta ropa (Acevedo, 2012: 134-135; 138-139; 144; 158-160).

En otras palabras, las mutaciones en la comprensión y explicación de los problemas sociales y culturales establecieron una distancia que media entre la fundación y los proyectos educativos y culturales que promovió la Secretaría de Educación Pública (SEP), en 1921, y las funciones que se le encomendaron al Departamento de Psicopedagogía e Higiene, dependencia de la propia SEP creada en 1925, entre el apoyo personal y comprometido del primer titular de esa secretaría, José Vasconcelos, y la reorientación de la tarea educativa de sus sucesores, José Manuel Puig Casauranc y Moisés Sáenz, con la introducción de la escuela racionalista y de la escuela para la acción.

Vasconcelos, inicialmente, promovió una intensa y completa política educativa y cultural que involucraba, entre otras cuestiones, campañas a nivel nacional de desfanatización religiosa, de higiene sexual y de combate al alcoholismo. Su política cultural también comprendió múltiples actividades como la difusión y edición masiva de libros clásicos, la fundación de instituciones culturales, entre ellas las misiones culturales, las "Casas de Pueblo", la escuela rural y las normales regionales, así como la educación media y superior. En contraste, Puig y Sáenz limitaron su influencia a la educación rural en su sentido más restringido y a favorecer la educación técnica (Urías, 2007: 16; Loyo, 1999: 126-152, 217-235, 255-280; Vásquez, 2000: 147-170).

De esta manera, se fortaleció una estrategia de intervención, la cual Se hizo evidente en el cada vez mayor empleo de las instituciones educativas, culturales y científicas para el examen, diagnóstico y orientación a los sujetos que presentaban "desviaciones" sociales, psicológicas o morales. Así, el estudio estaría dirigido a identificarlos por medio de la aplicación de pruebas y test para que, con base en sus resultados, se aplicaran las medidas correctivas que demandaba su condición (Loyo, 1999: 228-229).

\section{De la asistencia y la protección social a la educación correctiva}

Las elites políticas concibieron, dentro del programa de "ingeniería social", algunas instituciones sociales, teniendo un interés particular, las de la beneficencia pública y privada, al concebirlas como un pilar en el proceso de regeneración social y de reconstrucción estatal. Con este objetivo, en noviembre de 1920, el Ejecutivo federal dio los primeros pasos para reorganizarlas porque afirmaba que tal como funcionaban no satisfacían la finalidad que 
tenían encomendada. Así, su titular, Álvaro Obregón, envió al poder legislativo una iniciativa de ley que, entre otros aspectos, definía su objetivo que era el de "remediar las necesidades imperiosas de los desamparados", y estipulaba la creación de la Dirección de la Beneficencia Pública como una institución de Estado, la cual se encargaría de cumplir con ese objetivo. Dicha dirección estaría presidida por un consejo compuesto de seis personas (González Navarro, 1985: 170).

Cuatro años más tarde de haberse aprobado la iniciativa presidencial, se prescribieron las bases jurídicas para reorganizar todo su andamiaje institucional, introduciéndose una modificación sustancial: el término beneficencia fue sustituido por el de asistencia pública, hecho no menor, pues reconocía que ésta era un derecho social que el Estado tenía la obligación de garantizar, tal y como estaba consagrado en varios artículos de la Constitución de 1917. Esta definición suprimió el carácter de ayuda o socorro que se había mantenido en el marco del paradigma católico de la caridad y del espíritu laico de la filantropía. En este sentido, se establecieron disposiciones que tenían el propósito de alentar y organizar la beneficencia privada, que se estimaba muy importante debido a las funciones sociales que desempeñaba. En efecto, su importancia y su presencia tanto social como económica era notoria: en 1922, se calculaba que había un capital aproximado de 35 millones y medio de pesos invertido en asilos, colegios, hospitales, casas de estudiantes, montepíos, fundaciones de socorro y sociedades mutualistas, en los que se había asistido a un millón 200 mil personas. Dos años después, su patrimonio ascendía a 41 millones 200 mil pesos y patrocinaba 44 instituciones de beneficencia (González Navarro, 1985: 172).

Una muestra más del papel que las autoridades políticas le reconocían a la asistencia privada fue la colaboración del gobierno del Distrito Federal con la Asociación Mexicana Humanitaria, cuyo objetivo principal era la protección de los niños desvalidos, proporcionándoles "hogar a los que carecen de familia y que duermen en plazas, zaguanes, portales y calles de la ciudad y que no reciben ninguna educación que los prepare para la lucha diaria", además de la expedición de 25 credenciales a los socios del Rotary Club, quienes se encargarían de "hacer una exploración en los lugares indicados a efecto de llegar a conocer el número aproximado de los niños de que se trata y proceder, desde luego a ministrar los beneficios enumerados", así como disponer de la policía local para prestarlos auxilios que solicitaran los integrantes de dicha asociación privada (Gasca, 1923: 21).

En este contexto, en 1930, en un extenso y detallado estudio sociológico de la mendicidad en la Ciudad de México, Ramón Beteta, Jefe del Departamento de Acción Educativa, Eficiencia y Catastro Rurales del Departamento del Distrito Federal, por encargo del Presidente de la Junta Directiva de la Beneficencia Pública, Moisés Sáenz, concluyó: 
[...] en épocas malas, los obreros, con frecuencia no tienen más alternativa que morirse de hambre o vivir de la caridad pública. La mendicidad es la forma más común de la segunda de las posibilidades mencionadas. No todos los trabajadores, claro está, se vuelven mendigos en las épocas difíciles; pero hay muchos que no tienen otro remedio. No es entonces extraño que pasen de 10,000 las personas que viven en instituciones de beneficencia en la Ciudad de México (Beteta, 1931: 33).

De este modo, las reformas legales que crearon la asistencia pública y la privada ilustran el interés de las autoridades federales, estatales y municipales por la protección a los sectores sociales más desprotegidos, en especial a la infancia y a la familia. En específico, las autoridades del Distrito Federal se hicieron eco del programa de ingeniería social. Para éstas, la sociedad mexicana requería de una amplia y "verdadera labor reconstructiva en todos los ramos de la vida social". Las ideas que se esbozaron develan los alcances de la "revolución antropológica", primero, y de la intervención psicopedagógica, después.

La primera abarcaba, según sostenían las autoridades del Distrito Federal, atender los problemas sociales más acuciantes que afrontaba el país, entre los que señalaban "una más equitativa distribución de la tierra" y un mayor acceso a la educación pública, cuestiones que facilitarían "terminar para siempre con la injusticia que significó el hecho de que los beneficios de la cultura fueran un privilegio de los menos". Luego, aun cuando no estuvieran resueltos del todo, dirigir gran parte de los esfuerzos nacionales hacia la lucha contra el crimen y la delincuencia, la cual debía traducirse en una obra "legislativa y prácticamente en manifestaciones de técnica penal y correccional”. De este modo, se garantizaría que el país se dirigiera hacia "un fin de progreso material y moral".

Por principio, dicha obra requería de amplios y pormenorizados estudios para averiguar, "con precisión científica", los factores sociales e individuales que determinaban esos problemas y para sustituir los "anticuados sistemas de prevención y represión". De ahí la urgencia de fomentar los estudios para profundizar en la comprensión de la ley penal, las prisiones y las prácticas preventivas y represivas, constituyéndose en un "amplio campo de experimentación". Una vez obtenido ese saber, era posible enfrentar el evidente fracaso del combate en contra de esos problemas (Gasca, 1923: 19).

En conformidad con esta idea, a iniciativa del gobernador del Distrito Federal, Celestino Gasca, se realizó el Primer Congreso Criminológico y Penitenciario mexicano, y que, según sus organizadores, era una pieza clave para la "labor reconstructiva" en todos los ramos de la vida social en México. Un breve repaso a los trabajos del congreso permite tener una imagen de las medidas que se propusieron y los cambios que implicaba esa labor, entre los cuales destacaban, el diseño de nuevos métodos de corrección, regeneración y aislamiento de los "elementos temibles" que desterraran la idea de que los reformatorios y los establecimientos penales eran 
"montones de piedra y ladrillo", cementerios "para hombres vivos" o "escuelas de crimen y vicio" (Gasca, 1923: 22-23).

La agenda que debatieron los congresistas cubría una gran cantidad de temas: interpretaciones acerca del crimen, organización judicial, legislación penal, asistencia pública y privada; diseño de nuevos espacios educativos, métodos y recursos para identificar, seleccionar a los débiles mentales y proponer modalidades de educación especial para niños abandonados y con hábitos antisociales; examen de las aportaciones de nuevas o renovadas disciplinas, como la antropología y la psicología y su influencia en los métodos pedagógicos; relaciones entre el régimen penitenciario y el nivel cultural y moral de las sociedad, así como la "liga estrecha" entre los recintos penales y los hospicios, las deficiencias de las instituciones y las prácticas policiales y sus efectos en la numerosa población penitenciaria. En su conjunto, se trataba de reunir una gran cantidad de materiales que permitieran identificar, clasificar, controlar, atender y proteger a grupos de población específicos, todo lo cual traería "más paz y entendimientos recíprocos en nuestra vida escolar y la del hogar".

El congreso se dividió en diferentes secciones: médica, sociológica -que se dividió en las secciones de jurídica y antropológica-, psicotecnia e higiene mental, educativa y administrativa y de acondicionamiento de los establecimientos penales y correccionales, a fin de examinar varias cuestiones fundamentales. Un tema que se estudió y se debatió con amplitud fue el del delito. De hecho, se recomendó que los congresistas presentaran trabajos acerca de la delincuencia infantil y femenina, así como de delitos contra el pudor y el orden de las familias, de menores delincuentes y tribunales juveniles. No deja de llamar la atención que, en la sección de psicotecnia e higiene mental, se hubiera destinado una mesa para el análisis de la "relación entre el coeficiente intelectual del obrero y su capacidad de trabajo en la Industria Perfeccionada", y que se destinara otra para indagar en torno a la importancia de separar a los adultos de los sujetos inapropiados, entre quienes se encontraban anormales, niños vagos y delincuentes ocasionales o "poco temibles" y, de este modo, hacer eficiente el tratamiento higiénico mental en los establecimientos penales, entre los que se contaban reformatorios y casas de trabajo. En cuanto a la sección de educación, se sugería profundizar en la observación médico-pedagógica y las clases de instituciones educativas para los niños que "caen en poder de la justicia" por estar "incapacitados de vivir en la sociedad sin conflictos con la ley".

Como puede apreciarse, la organización temática del congreso permite tener una idea de las disciplinas, los especialistas y los saberes que se concurrían a este campo de conocimiento e intervención, entre ellos profesores, psicólogos, abogados y médicos, así como sociedades científicas y patronatos de débiles mentales, unos y otros "con preparación y entendimiento" por su tarea especial en un establecimiento penal y correccional. A manera de ejemplo de la colaboración entre disciplinas científicas y especialistas en la construcción 
de un nuevo campo de saber en México están los integrantes del comité organizador y de las secciones respectivas del congreso. De 59 miembros, 10 tenían el título de licenciados, 14 de profesores, 16 de doctores, tres militares y 16 no registraron título. Los doctores dominaban la sección médica, mientras que los profesores dominaban la sección de educación con 15, donde se incluía un médico; en la sección sociológica, jurídica y antropología, había mayoría de licenciados, en tanto que la sección de psicotecnia y de higiene mental se guardaba un mayor equilibrio al haber la presencia de médicos, profesores, doctores y otros. La sección administrativa y de acondicionamiento de establecimientos penales se integraba por dos profesores, dos militares y tres de otros. En la presidencia del Comité Organizador estaban representados licenciados (tres), médicos (tres), profesores (uno), militares (uno), todos ellos presididos por Celestino Gasca (Gasca, 1923: 22; 25-26; 28-31).

En esta tesitura, otras iniciativas que el gobierno del Distrito aprobó y apoyó fue la solicitud de Director de la Facultad de Altos Estudios de la Universidad Nacional de México para que se permitiera a sus profesores impartir educación en las cárceles y penitenciarías del Distrito Federal, con lo cual contribuirían a convertir esos establecimientos en lugares de regeneración. Tal apoyo se otorgó después de un "concienzudo estudio" en el que se concluyó que el gobierno tenía la obligación moral y material de "buscar la regeneración de los reclusos que por cualesquiera circunstancias se encuentran en las cárceles..." (Gasca, 1923: 18-19; 23).

Otro evento de gran significado fue la celebración del Primer Congreso Mexicano del Niño, convocado por el periódico El Universal y celebrado en la Ciudad de México en 1921 ?. Dicho evento logró reunir a representantes de distintos ámbitos sociales preocupados especialmente por la niñez mexicana. La diversidad de personajes, posturas, disciplinas e instituciones que concurrieron al evento permite tener una imagen completa de los problemas que enfrentaba la infancia mexicana. ${ }^{8}$ Durante sus trabajos no faltaron la exposición y el debate acerca de las condiciones y necesidades de la infancia, sobre todo de aquella que se encontraba en condiciones sociales desfavorables, entre ellas la pobreza y sus secuelas más preocupantes, la desorganización familiar, el abandono, el desamparo, la ausencia de protección social, la miseria y la indigencia. Frente a esta problemática, uno de los temas que se pusieron a discusión fue quién y cómo debería de intervenir y participar el cuidado de la infancia.

\footnotetext{
${ }^{7}$ Ejemplos de las preocupaciones que tenían las élites políticas y sociales en torno a la infancia en estos años pueden encontrarse en Susana Sosenski, 2006

${ }^{8}$ De acuerdo con del Castillo, desde finales del siglo XIX, la convergencia de médicos y pedagogos hizo posible una mirada médico-pedagógica que se enriqueció con las aportaciones de la psicología experimental. De este modo, una nueva comprensión de la infancia, en especial de la naturaleza de los cuerpos y las mentes infantiles, se divulgó no sólo entre los círculos académicos sino que se amplió hacia otros sectores y grupos sociales preocupados por la suerte de la infancia. Como ya se ha hecho notar, esta mirada permeó y se profundizó en los espacios públicos que se abrieron entre 1920 y 1940 en el marco de la creación o readecuación de las reflexiones e instituciones educativas y sociales que patrocinó o promovió el Estado mexicano posrevolucionario (Del Castillo, 2006: 135).
} 
Desde luego, el interés por esas cuestiones llevó a discutir la importancia y la función de las instituciones de beneficencia pública y privada, el papel del Estado y la Iglesia, de los filántropos y las asociaciones científicas, de la caridad y la limosna, del derecho a la protección social, de la familia y la escuela (Memoria, 1921).

El congreso se dividió en cinco secciones, en las cuales se debatieron múltiples temas y problemas. Las secciones fueron: eugenia (sic), pediatría médica, higiene, enseñanza y legislación penal. Aquí nos detendremos a examinar la sección de legislación infantil porque en ella se discutieron con mayor detalle las medidas tutelares y de protección para la infancia que habría de asumir el Estado mexicano, así como el lugar de la beneficencia pública y privada. En gran medida, esta sección fue la síntesis de todos los trabajos y de las iniciativas para proteger a la infancia.

Una de las propuestas que más llamaron la atención fue, sin duda, la creación de los Tribunales para Menores Delincuentes. Aunque no sabemos con exactitud las modificaciones que tuvo el proyecto que presentó el licenciado Manuel Cruz, a nombre del Tribunal Superior del Distrito Federal, no deja de tener interés el análisis de diversos artículos porque muestran la lógica médico jurídica que predominaba, aunque con un fuerte componente pedagógico. Conviene destacar que ese proyecto también es una demostración del paradigma de la familia, de las funciones, las obligaciones y las responsabilidades de cada uno de sus miembros. En otras palabras, se esbozan un conjunto de representaciones de la organización familiar, del padre, la madre, el niño o la niña, de los y las adolescentes y jóvenes, cuyo propósito no sólo era cuidar y proteger sino controlar y vigilar a la infancia.

Los tribunales para menores delincuentes se integrarían de tres personas, todas ellas abogados titulados, de moralidad y buena conducta notorias y con conocimientos de "los problemas sociales relativos a la educación y protección de la infancia". Esto, según el autor del proyecto, era imprescindible para garantizar y vigilar que sus resoluciones no afectaran "el orden y tranquilidad de las familias en que hubiere niños, y en cuanto a la enmienda, educación y moralidad de éstos". Para el desempeño de las labores, se recomendaba que fueran auxiliados por "personas privadas de cualquier sexo, de buena voluntad y sentimientos filantrópicos", esto es, asignaban un papel muy importante a los miembros de instituciones de asistencia privada (Cruz, 1921: 362-363).

Asimismo, se propuso la creación de dos modalidades de tribunales: el primero conocería de asuntos civiles y el segundo de asuntos penales. El Tribunal Civil para Niños conocería de asuntos relacionados, entre otros, con la obligación de las madres de atender a los menores que estuvieran bajo su cuidado, garantizándoles la lactancia, así como a atender y resolver las solicitudes de los padres para imponer los castigos y correcciones "mesurados" que consideraran pertinentes a fin de que sus hijos les guardaran "obediencia y respeto". De igual manera, tendría la facultad de obligar a los hijos a volver a "la casa paterna" en caso de 
que la hubieran abandonado, así como a imponer a las hijas solteras, mayores de edad 18 años, pero menores de treinta, a regresar "al lado de su padres o madre en cuya compañía vivían", siempre y cuando existiera causa justificada para ello. También se les facultaría para resolver los casos en que se solicitara el ejercicio de la patria potestad, se pidiera la misma a "personas altruistas"; en este caso, estas debían comprobar que habían protegido y cuidado a menores, o bien cederla en caso de menores en "estado de abandono". Como puede apreciarse, dicha iniciativa implicaba un amplio espacio de intervención de las autoridades judiciales en la vigilancia del hogar y estaban directamente vinculadas con la familia (Cruz, 1921: 363).

Igualmente, había una serie de artículos en los cuales se trataba el problema de la infancia abandonada. En ellos destacan las facultades que se le conferían al tribunal civil de conocer de las peticiones para "prestar amparo y protección" a los menores que no hubieran cumplido 18 años, los cuales podían ser enviados a instituciones de beneficencia pública o privada, entregados a particulares "de sentimientos filantrópicos", quienes los educarían, los atenderían "moral y materialmente" o bien les proporcionarían "trabajo honesto" que les redituara lo suficiente para cubrir "sus necesidades morales y materiales". En esta última circunstancia, el tribunal autorizaría los contratos de trabajo y aprendizaje y velaría por su cumplimiento (Cruz, 1921: 364). ${ }^{9}$

En cuanto al Tribunal Penal para Niños, su función y sus atribuciones eran especialmente delicadas en cuanto que se trataría de menores que estaban involucrados en delitos. De ahí la importancia de proceder con cautela. Por principio, el tribunal estaría obligado a realizar averiguaciones que tomaran en consideración la edad, la existencia y las circunstancias del hecho, la participación de los menores, "la situación material y moral del niño y su familia", así como las condiciones en que había vivido y había sido educado. Un asunto de primer orden era determinar si el menor de entre 9 y 14 años podía o no obrar con discernimiento porque de ello dependía continuar o no con las diligencias y concluir con una sentencia condenatoria, aplicarle la pena correspondiente o, en caso contrario, cerrar la indagatoria, cuestión que tocaba resolver al cuerpo de especialistas. Esto necesariamente requería de un cuerpo de especialistas versados en temas médicos, legales y pedagógicos capaces de diagnosticar su estado de salud, su desarrollo físico, intelectual y moral y "las demás circunstancias que puedan tener interés en la apreciación cabal del asunto" (Cruz, 1921: 365).

Con base en estos estudios, el tribunal podía decidir si el niño era devuelto a sus padres, tutores o encargados, siempre y cuando poseyeran las virtudes de moralidad y honorabili-

\footnotetext{
${ }^{9}$ Acerca de la mendicidad, Ramón Beteta sostenía que se trataba de una institución y resumía: "Desde el punto de vista del sociólogo, los pordioseros y la "institución" (entrecomillado en el original) de la mendicidad, son fenómenos patológicos. Como el crimen, como la delincuencia juvenil, como la prostitución, la mendicidad representa un desajuste en el funcionamiento normal del individuo y del grupo. Por otra parte, el pordiosero es esencialmente un individuo desmoralizado y desadaptado, y la "institución" de la mendicidad es un síntoma de desorganización social" (Beteta, 1931: 17)
} 
dad para garantizar la seguridad de los menores; de no reunir estas cualidades, entonces se procedería a ponerlo bajo el cuidado y la custodia de personas honorables o en "establecimientos adecuados". De esta manera, el tribunal atendería la averiguación, las correcciones y el castigo de los delitos que se imputaran a los menores de dieciocho años y, dentro de sus atribuciones, ordenar que el menor fuera colocado en "familia honorable distinta a la suya", el internamiento en escuela, asilo u "otro establecimiento de beneficencia pública o privada", de acuerdo con las circunstancias que presentara el menor hasta que cumpliera la mayoría de edad, o colocarlo en talleres o establecimientos industriales por un periodo no mayor de seis años e inclusive estarían facultados para realizar contratos de trabajo o aprendizaje, siempre que los padres no lo hicieran. Finalmente, el tribunal resolvería las solicitudes de libertad preparatoria que los infractores presentaran, las cuales podían resolverse independientemente de la pena aplicada (Cruz, 1921: 365).

En este mismo asunto, esto es, la creación de los tribunales para menores, participó activamente la licenciada María A. Sandoval de Zarco, quien subrayó la importancia de reformar los códigos y las leyes a fin de elevarlos "a la altura de progreso y la cultura que tanto proclamamos". Sandoval, en representación de la Sociedad Protectora del Niño, trazó un cuadro que, según ella, eran las circunstancias en las que vivían muchos "seres pequeños y desvalidos":

\footnotetext{
Protestemos contra el espectáculo que ofrecen esos mismos niños sin hogar, recorriendo en el día, semidesnudos las calles voceando periódicos en una lucha terrible con la vida, para alcanzar el pan suyo y a veces de los suyos también; finalmente, cuando quizás agotados o vencidos en la lucha, cometen una falta o un delito, se les lleva hasta ocupar el banquillo de los criminales en un salón de Jurados donde a la sola presencia de esos niños, el ambiente se satura de lágrimas y vergüenza (Sandoval de Zarco, 1921: 366).
}

Además postuló la urgencia de crear una institución que tuviera como objetivo juzgar y resolver cuestiones referentes a la niñez delincuente. Inspirada en los ejemplos de otros países, propuso la creación de Cortes Juveniles. Para sostener su propuesta, Sandoval aseguraba que el mayor número de criminales provenían de "medios o clases bajas" donde era común la falta de educación y de cultura, lo que "necesariamente" daba por resultado que adquirieran "malos hábitos". De ahí la necesidad de trabajar para preparar "en el niño al hombre del porvenir" y esto sólo era posible mediante la construcción de cimientos sólidos y sanos en el seno de las familias. Sugería que ante la ausencia de estos, se fundaran albergues que fueran "verdaderos hogares" donde los niños recibieran pan, educación e instrucción "haciéndolos útiles ciudadanos" y con ello evitar que delinquieran. 
Sin embargo, Sandoval reconocía que dichas acciones no eran una garantía suficiente para prevenir los delitos y por lo tanto era indispensable el establecimiento de las Cortes Juveniles, que se encargarían de juzgar a menores delincuentes, evitando la "infamia" y que se les abrieran "las puertas de un porvenir tenebroso de verdaderos criminales". De este modo, Sandoval proponía un tribunal especial que no sólo juzgara y castigara sino que, sobre todo, se destinara al estudio de los instintos, del carácter, de las inclinaciones y todo lo que formara el "ser moral" del niño.

La abogada no tenía la menor duda de que los maestros eran los especialistas por excelencia para esta labor por su amplio conocimiento de la naturaleza infantil, por lo que éstos deberían integrar las cortes o tribunales especiales, aún más que los médicos, abogados o psicólogos, puesto que "son los que han vivido y viven entre los niños; quienes los han seguido en su vida más de cerca y por consiguiente los que más los conocen y los interpretan". Para Sandoval, los maestros estaban preparados para poder penetrar en "el alma delicada del niño", en contraste con los jueces correccionales, quienes no podían comprenderlo por estar alejados "de esos pequeños seres" y aseguraba que no podía ser de otro modo porque estos conocían de asuntos relacionados "con hombres delincuentes". En suma, para Sandoval se requería de las cortes juveniles conformadas con "pedagogos competentes", cuyo objetivo no era imponer una condena sino reformar los hábitos y costumbres para devolverlos "al seno de la sociedad" ya regenerados y "no convertidos en criminales con penas extinguidas".

Sandoval también consideraba que el establecimiento de estas cortes o tribunales tendrían que complementarse con reformas a la legislación penal para imponer penas severas a quienes instigaran a los menores a cometer infracciones, entre ellas la mendicidad, la vagancia o el ocio, sirviéndose de ellos como "medio de verdadero lucro", o bien a la comisión de delitos. De igual manera, recomendaba que los infantes abandonados por orfandad o por cualquier otra causa fueran enviados a establecimientos para niños sin hogar y retirar la patria potestad a quienes fueran incapaces de dirigirlos y educarlos por "el sendero de la honradez y el trabajo".

Por último, sugería establecer auténticos "hogares-escuelas", junto a las cortes, para albergar, alimentar y capacitar a los niños recogidos del "arroyo" en un oficio, industria o trabajo, por medio de la instalación de talleres, destinándolos al conocimiento de los "ramos de la industria humana según sus inclinaciones y aptitudes", y haciéndolos "útiles a sí mismos y a sus semejantes" (Sandoval de Zarco, 1921: 3, 67).

Por su parte, el penalista Antonio Ramos Pedrueza, encargado de recoger y presentar las conclusiones de esta sección, recomendó la creación del Tribunal para Menores Delincuentes en el Distrito Federal, los que conocerían de todos los procesos en los cuales estuvieran involucrados menores de 18 años. Tal dependencia se integraría de dos médicos especialistas en psiquiatría y un abogado con práctica especial en materia penal "cuando menos de quince 
años", quien lo presidiría. Un dato a subrayar en las conclusiones de Ramos era el procedimiento que debería seguirse en el interrogatorio del menor, el cual tendría que ser paternal a fin de ganarse la confianza de éstos, "haciéndole comprender" que no se trataba de castigarlo, sino de educarlo y moralizarlo", así como procurarle conocimientos útiles "despertando en él sentimientos de honradez y de rectitud".

Además señalaba la pertinencia de crear colonias agrícolas por el tiempo que el tribunal juzgara "prudente" para quienes se les había impuesto la pena de reclusión. Coincidía en proponer que el tribunal evaluara la conveniencia de depositar en el "seno de una familia honrada" en calidad de huérfana si se trataba de una menor delincuente. Una novedad que se presentó dentro de las recomendaciones fue considerar las ventajas que traería la participación de sacerdotes en los planteles correccionales y en las colonias para menores delincuentes, quienes tendrían libre acceso si bien se sujetarían a los reglamentos y a la autoridad del tribunal, "que será el superior absoluto de todos estos establecimientos" (Pedrueza, 1921: 368).

Años después de celebrarse este congreso, en 1929, el doctor Gilberto Bolaños Cacho reiteró la necesidad de que los infantes infractores fueran examinados por otros especialistas y no únicamente por los jueces de lo penal, porque "era necesario que fueran individuos preparados especialmente en psicopedagogía, en sociología, y en asuntos menores de conducta irregular los encargados de conocer todos estos problemas". Además, consideraba que esto era posible por la naturaleza propia de los infantes, es decir, por las posibilidades de su rehabilitación social y moral y de su incorporación a la vida productiva. Bolaños consideraba que la infancia estaba compuesta de una "substancia (sic) plástica, moldeable, inmadura, inexperta" que carecía del "sentido de responsabilidad" por lo que era "susceptible de modificarse, de moldearse, de transformarse, siempre en beneficio suyo a través de tratamientos psicopedagógicos y rehabilitantes (sic) y no punitivos como los adultos" (Bolaños citado en Azaola, 1990: 54).

Una primera institución creada en este sentido fue el Departamento de Psicotecnia e Higiene Mental, fundado en febrero de 1922, el cual atendía a los reclusos de la Penitenciaría del Distrito Federal, fundada en septiembre de 1910, y de las escuelas correccionales. Su propósito era estudiar "la psicología humana en general, y la particular de los delincuentes" por medios experimentales y, con ello, tener elementos para su clasificación que permitiría formular el tratamiento conveniente y que sería llevado "a la práctica por los gabinetes que deberían quedar anexos a cada establecimiento". De acuerdo con Gasca, la labor desempeñada por dicho departamento había sido primordial porque había permitido mostrar que la población en esos establecimientos era heterogénea, de tal manera que no era posible aplicar un tratamiento común y, más aún, que muchos de ellos no representaban un peligro para la sociedad, aunque los había, por lo que era imprescindible organizar un sistema para lograr 
su libertad "antes que la separación de sus familiares y de la vida normal" dejaran "sus huellas irremediables sobre su psiquis".

Durante el primer congreso criminológico en México, se hizo referencia a la necesidad de contar con "hombres preparados" para recoger y examinar datos de la observación y la experiencia en los establecimientos penales y correccionales, tales como profesores, psicólogos y médicos con disposiciones y entendimiento de su tarea especial, así como la participación de las sociedades científicas. Con su saber, estos contribuirían a la selección temprana de los débiles mentales, la educación especial de niños abandonados y con hábitos antisociales y demostrarían a los responsables de la beneficencia pública los nexos estrechos entre los hospicios y los recintos penales (Gasca, 1923: 22-23).

Cabe destacar que estas iniciativas se apoyaban, en gran medida, en una interpretación que asociaba la desorganización familiar con conductas antisociales y anormales de la infancia por lo que su interés se encaminaba a contener los posibles peligros que ésta representaba, aunque bajo una tesis que postulaba el reconocimiento de los derechos del niño. En el trabajo sociológico sobre la mendicidad en la Ciudad de México, Ramón Beteta recogió testimonios de mendigos y vagos de diversas edades, condición social y géneros. Uno de ellos se refiere a la historia personal del menor de 12 años, Trinidad Méndez, en la que da cuenta de su amplia trayectoria en la institución de la mendicidad. Este es un ejemplo preciso de lo que las autoridades definían como la infancia moral y socialmente abandonada. Según el testimonio de Méndez, su padre era panadero y a los 16 años contrajo nupcias con su madre, quien a la fecha de matrimonio tenía de 13 años. Durante tres años mantuvieron una relación matrimonial estable hasta que las diferencias entre ellos se volvieron insalvables debido a las infidelidades del esposo y el carácter impulsivo de ella. El padre bebía con frecuencia, en tanto que la madre empezó a desatender a los hijos, hasta el grado en que el primero decidió abandonar a su familia al igual que la madre, quien a su vez sostuvo numerosas relaciones sexuales. Ante esta situación, evocaba Méndez, su madre asumía con mayor frecuencia una conducta "desordenada" y violenta contra sus hijos e hijas, por lo que el menor había decidido huir de su casa para comenzar la carrera de mendigo y vagabundo (Beteta, 1931:79-80).

Beteta expuso sus ideas acerca de los factores que explicaban el tipo de familia en la que se había desenvuelto Méndez, la naturaleza y el funcionamiento de las sociedades urbanas, como era el caso de la Ciudad de México, la cual había tenido una expansión geográfica y un crecimiento poblacional desmedido, factores que a juicio del funcionario influían en el deterioro de las relaciones familiares y, por añadidura, en el debilitamiento de la familia como un mecanismo de control social primordial, así como las razones por las que el menor se había dedicado a ejercer la mendicidad: 
La ciudad representa el último extremo de lo que puede llamarse "sociedad secundaria". En ella, el control sobre los miembros del grupo que necesita cuidado y vigilancia, es formal en carácter y contrasta grandemente con el que existe en el "tipo primario" de los pueblos pequeños. En la ciudad el control es flojo y transigente; en el pequeño poblado es íntimo y afectivo; en aquélla la vigilancia se deja a las agencias externas de la ley y el Gobierno; en éste el cuidado es de la persona. La ciudad demanda movimientos más rápidos de parte de sus habitantes; porque aumenta el número y variedad de contactos personales e intensifica la lucha de posición social al acelerar la competencia: utiliza más a los agentes del saber y menos a las capacidades nativas... El individuo que no puede adaptarse a sus demandas, que no puede adquirir las costumbres y aptitudes que pide este gran grupo secundario, será el adaptado que en una forma o en otra llegar a ser un problema para la misma sociedad que lo crea (Beteta, 1931: 83-84).

En particular, Beteta consideraba que en las ciudades esos problemas sociales se agudizaban y ponía como ejemplo a la capital del país:

La capital de México, durante las dos últimas décadas, ha llegado a ser un gran centro metropolitano. Como tal, exhibe en manera creciente el fenómeno patológico de la desorganización de personas y familias característico de las grandes ciudades [cursivas mías]. Y en verdad, el fenómeno de desorganización a que nos referimos ha sido el más serio en la Ciudad de México que en otros centros urbanos extranjeros, debido a que el rápido crecimiento se ha producido en gran parte como el resultado de numerosos grupos de individuos provenientes de pequeños poblados y rancherías, en las que la mayoría del pueblo de México ha vivido desde tiempo inmemorial.

Precisamente a esta gente que viene del tipo "primario" es a la que se le dificulta más el ajustarse a las demandas del grupo "secundario" y a la que con más frecuencia encontramos embrollada en juicios criminales, en hospitales, en asilos y, en general, en todos los lugares a donde van a parar los que tienen dificultades serias por inexperiencia (Beteta, 1931: 83-84).

En esta dirección, un paso más fue agregar la idea de debilidad social, la cual se definió como las dificultades que presentaban los individuos que les impedían incorporarse al proceso de producción, entre los niños y las niñas que padecían circunstancias adversas y, por añadidura, no estaban en condiciones de hacerse cargos de sí mismos: desde menores que provenían de familias desintegradas hasta los niños anormales, quienes requerían no sólo de un tratamiento pedagógico, psicológico o social especial sino de inculcarles y fomentarles hábitos de disciplina y trabajo para incorporarlos a la vida productiva. Por lo tanto, la definición y las funciones de la asistencia y de la protección social debían alcanzar a aquellos que se encontraban en condiciones de debilidad social (González Navarro, 1985: 190-193). 
A manera de ilustración del pensamiento social que predominaba en la época retomamos el testimonio del niño Trinidad Méndez que recogió Beteta y que, después de presentarlo, lo interpretaba de la siguiente manera:

A primera vista se percibe que Trinidad es el producto y la víctima de la libertad de que se goza en las ciudades. El área que ha llegado a tener la Ciudad de México en los últimos años explica que un niño pueda andar vagando por las calles fuera del control de la familia, sobre todo de la familia normal que existe en las pequeñas comunidades. Trinidad es vago y mendigo; pero su conducta se entiende y explica recordando el hogar desintegrado (cursivas mías) en donde los estudiantes de la vida citadina, pueden ver la historia poco novedosa de alcoholismo, y de conducta sexual irresponsable de quienes se encuentran imposibilitados para ajustarse a la tirantez y las demandas de esta situación irregular (Beteta, 1931: 81-82).

\section{Instituciones paradigmáticas: la educación correctiva}

Como puede observarse, los establecimientos de asistencia pública y privada fueron transformados en instituciones de educación correctiva, entre cuyos objetivos estuvo ser laboratorios para el estudio de las enfermedades, la conducta y la mente humanas. Por tal razón, es pertinente detenerse en el análisis que los especialistas formularon acerca de la función de este tipo de establecimientos, en particular de las escuelas correccionales y educativas para varones y mujeres, en la medida en que desvela las prácticas discursivas y las educativas así como la racionalidad que las autoridades políticas buscaban introducir. Si bien estos planteles caían en la esfera penal, su lógica interna, su organización y sus objetivos estaban en consonancia con algunas de las ideas regeneracionistas, paradigma científico que compartían las autoridades, gran parte de los especialistas y las comunidades científicas, así como con los fines que se perseguía con ellas, es decir, de intervención social y educativa.

Los "corrigendos" eran sujetos de un proceso profiláctico y pedagógico a fin de alcanzar su regeneración. Gasca observaba que esos planteles debían inspirarse en un "espíritu paternal", muy a tono con la construcción de un estado corporativo, como lo señala Beatriz Urías, en la medida en que estaban destinados a menores. Su principal tarea era la formación de espíritus aptos "para luchar por la vida" lo que en otra palabras significaba "ser Capaces de utilidad personal y social", de satisfacer sus necesidades materiales y adaptarse al orden social, muy a tono con el discurso de la revolución antropológica.

Por eso la educación en esos establecimiento tenía que ser práctica y utilitaria lo que suponía el diseño y ejercicio de programas, materiales y horarios especiales, así como clases 
de instrucción primaria y el aprendizaje de oficios, "procurando la más perfecta armonía entre los conocimientos proporcionados por la escuela primaria y los aprendizajes industriales", para "darle una preparación práctica que lo ponga en condiciones de ganarse fácil y honradamente la vida al salir del establecimiento" y de este modo lograr la reforma moral del interno.

Uno de los aspectos más notables de tales instituciones fue que reforzaron el estudio de la infancia anormal en tanto que los sujetos ahí albergados eran considerados como parte de la misma y por lo tanto sujetos de un proceso educativo especial (Gasca, 1923: 50, 60-62). En gran medida, esas propuestas se inscribían en un discurso que asociaba desorganización familiar con conductas antisociales y anormales, lo que explica el interés por contener los posibles peligros que esta infancia representaba, aunque bajo una tesis que postulaba el reconocimiento de los derechos del niño.

De esta manera, los establecimientos de asistencia pública y social fueron concebidos como laboratorios para el estudio de las enfermedades tanto de la conducta como de la mente humana. Ejemplos de estos esfuerzos fuer la idea de crear en noviembre de 1920, el Tribunal Protector del Hogar y la Infancia, incluido en un proyecto de reformas a la Ley Orgánica de los Tribunales del Fuero Común. En esta tesitura, la casa de cuna fue calificada de "centro de perfeccionamiento de los médicos de niños en la Ciudad de México", donde prestaban sus servicios seis facultativos, "de los más conocidos". De ahí el cuidado que ponían las autoridades correspondientes para contar con las instalaciones más adecuadas y con el mobiliario más completo. En 1932, se adquirió mobiliario "preciso y magnífico", se abrieron juegos de salón, de ocupaciones, de cantos y juegos, se acondicionó una biblioteca con "deliciosos cuadernos y estampas" y se inauguró "una cocinita para prácticas del hogar" (Velasco, 1935: 120).

Un hecho que da cuenta de la importancia que había cobrado la influencia del aspecto pedagógico fue la creación, en 1925, del Departamento Psicopedagógico, dependiente de la Secretaría de Educación Pública, la cual debía atender a todas las escuelas primarias, fueran urbanas o rurales y la fundación, en 1924, de la Primera Junta Federal de Protección a la Infancia. En este contexto, en el año 1926, el Ejecutivo federal puso el acento en "la necesidad de dar una amplia protección a la infancia delincuente, moral y legalmente abandonada" lo que implicó ser una medida más, para reorientar las funciones de las escuelas correccionales, las cuales tendrían como propósito lograr la reforma de los menores infractores. En esta dirección, un par de años después, se reformuló la Ley sobre Previsión Social en el Distrito Federal que extendía la labor del Tribunal a los niños abandonados y menesterosos, confiriéndole atribuciones para impartirles educación y satisfacer sus necesidades materiales. De igual manera podía ocuparse de los niños incorregibles cuando lo pidieran los padres o tutores. También en ese año, en el reglamento de la ley estipulaba la organización del tribunal. Las funciones que desempeñarían estas instituciones tenían que hacerse con un enfoque 
multidisciplinario que atendiera los aspectos psicológicos, médicos y pedagógicos. Así, por ejemplo, se estipuló que en esta institución funcionarían cinco secciones para el estudio de la personalidad del menor: la social, encargada de estudiar la personalidad del menor y prevenir la delincuencia infantil, la pedagógica, cuya tarea principal era investigar los antecedentes escolares y determinar sus conocimientos y aptitudes; la médica, que examinaría los antecedentes patológicos, hereditarios y personales; la psicológica que registraría y observaría el desarrollo mental, el carácter y la conducta y, por último, la sección de paidografía, encargada de elaborar la estadística del Tribunal (Castañeda, 1984: 22-23; Azaola, 1990: 52; Gasca, 1923: 22).

Ahora bien, en 1929, como parte de este programa de intervención psicopedagógica, el jefe del Departamento del Distrito Federal, José Manuel Puig Casauranc impulsó una serie de medidas administrativas que representaron una profunda transformación en los fines, las acciones y las instituciones encargadas de la atención y protección social que brindaba a la población en su conjunto, en particular del "proletariado" con el objetivo de "promover, desarrollar y mantener el espíritu cívico en los habitantes del Distrito Federal y contribuir al mejoramiento de sus condiciones sociales y de su vida de relación”. Entre otros aspectos, el proyecto incluía la creación de tres direcciones: de acción cívica, de reforma y cultural, a cargo del prestigioso médico Alfonso Pruneda; de acción recreativa popular, cuya responsabilidad recayó en la señora Amalia González Caballero Ledón; y de acción social y educación estética, bajo la conducción del profesor J.A. Ramírez (Departamento, 1929: 6-9).

Para dar una idea de los alcances de esa reforma baste señalar la gama de actividades que deberían de promover: desde acciones culturales hasta cívicas y deportivas dentro de los establecimientos de previsión y reforma social, entre ellas las escuelas que funcionaban en esas instituciones, así como las que pertenecían a los centros de reclusión y de corrección, entre los que se encontraban los tribunales para menores, los reformatorios, los preventorios sociales y los establecimientos penales, así como los locales escolares que habían estado bajo el patrocinio de los municipios del Distrito Federal. Para las autoridades del Distrito Federal la importancia de realizar esas actividades radicaba en la necesidad de brindar "un tratamiento verdaderamente humano... de acuerdo con las exigencias de la época" al mismo tiempo que se recomendaba profundizar en el análisis de las manifestaciones sociales que se consideraban anómalas, sobre todo la mendicidad, y los medios para combatirlas (Departamento, 1929: 9).

A partir de esa reorganización, el profesor Salvador Lima presentó, con base en las experiencias de los tribunales para menores, un Proyecto de Organización y Funcionamiento del Patronato de Hogar y de Trabajo del Departamento del Distrito Federal ante Puig Casauranc, quien aprobó dicha propuesta. Este proyecto reviste una riqueza tanto por las ideas como por las funciones y la lógica de asistencia pública y de "servicio social" hacia los sectores sociales más vulnerables que tenía el gobierno de esa entidad y que, sin duda, compartía 
el Ejecutivo federal mexicano. Unas y otras pretendían inducir renovar las prácticas institucionales en los establecimientos de protección a la infancia y a la familia. Conviene destacar que tal iniciativa se inspiraba en las experiencias de todo tipo que se habían acumulado a partir del funcionamiento de los tribunales para menores, los cuales pueden considerarse como el paradigma de la asistencia pública y de la protección social del Estado mexicano posrevolucionario (Lima, 1929).

Un paso más en este sentido fue el cambio de nombre de uno de los establecimientos más emblemáticos del anterior concepto de beneficencia pública y de su sustitución por el de asistencia social: el hospicio de niños que, a partir de 1930, se denominó "Casa del Niño". La introducción de estrategias pedagógicas y disciplinarias marcó una nueva racionalidad, cuyo objetivo primordial fue inculcar y reforzar los hábitos de trabajo y la idea del ciudadano productivo. Unas de las primeras medidas que se aplicaron fue organizar el trabajo de los menores por medio de faenas, así como introducir prácticas deportivas y excursiones para desarrollar "la vida sana y alegre". En esa institución se atendieron cerca de 1300 niños y niñas, entre cinco y diez años de edad, ya que al cumplir esa edad eran transferidos a la Escuela Industrial de Huérfanos.

Quizá una de las instituciones que mayores mutaciones presentó, según la racionalidad utilitaria y pragmática, fue la Escuela Industrial de Huérfanos que cambió su nombre por el de Escuela Industrial Vocacional con el propósito de orientarla a la enseñanza práctica y utilitaria. Así, el plantel se estructuró, en la década de los años treinta, bajo un régimen semimilitar y con un símil de funcionamiento familiar. Ejemplo de esto es el siguiente: a los alumnos se les aglutinaba en compañías, que se integraban por sesenta niños y jóvenes, las cuales quedaban a cargo de un vigilante, y familias, compuestas de doce y bajo la autoridad de un jefe, "el hermano mayor", quien era elegido por su buen comportamiento y era responsable de "ver por todas las necesidades de sus camaradas, cuidarlos y vigilarlos y atenderlos constantemente". Con esta organización se pretendía "descubrir" la vocación de los alumnos y prepararlos para recorrer el último tramo de la red escolar que conformaban las instituciones educativas y de asistencia social hasta concluir en el Centro Industrial Rafael Donde, en el cual se les adiestraba y perfeccionaba en el oficio o la carrera elegida. Para 1934, la escuela atendió a 469 alumnos, cuando su capacidad instalada era de 400 espacios (Departamento, 1929: 124-125).

En 1935, en la Ley Orgánica del Poder Judicial de la Federación se establecieron las atribuciones de los juzgados de distrito en materia de prevención y represión de la delincuencia de los menores de 18 años mediante la creación de tribunales para menores y consejos de vigilancia. La composición del primero variaba de acuerdo a la calidad de la jurisdicción correspondiente, mientras que los consejos estarían presididos por el miembro de mayor jerarquía de la beneficencia pública o, en su defecto, de la beneficencia privada a la cual se 
incorporarían "el número de vecinos de la localidad que se estime conveniente que no podría ser menor de diez", quienes tenían que cumplir entre otros requisitos con buena conducta comprobada y arraigo en el lugar, así como demostrar una manera honesta de vivir y ser padre o madre de familia (Secretaría, 1936: 30-31).

En 1937, estas transformaciones tanto en el pensamiento social como en las prácticas institucionales se vieron reflejadas en la creación de la Secretaría de Asistencia Pública que fusionó la beneficencia pública y privada y el Departamento Autónomo de Asistencia Infantil. De este modo, la asistencia pública se dirigiría a los indigentes, a los jefes de familia enfermos y a familias numerosas que no estaban en posibilidades de garantizar condiciones de vida dignas a sus integrantes.

\section{Reflexiones finales}

Como sucedió durante el siglo XIX, en las décadas de los años veinte a los cuarenta del siglo XX, se elaboró un pensamiento social que pretendía explicar algunos de los problemas sociales más agudos y las posibles alternativas para mitigarlos. En este marco, tuvo un lugar importante la polémica en torno a la función de la beneficencia pública y privada. Viejos y nuevos actores debatieron, entre ellos los representantes de la iglesia católica mexicana, de las elites políticas, de los empresarios, de los comerciantes y de las comunidades científicas, en especial médicos y pedagogos, expusieron sus ideas, percepciones y prácticas en torno a varios de los principales problemas sociales del país y las estrategias que habría que diseñar e impulsar para, en la medida de lo posible, resolverlos o al menos mitigarlos.

En realidad, estos debates eran una extensión de la polémica que durante estos años enfrentaba a diversos sectores sociales y políticos, aunque la novedad estaba en que el eje de sus disquisiciones fue notoriamente el niño mexicano y la intervención de otros actores, entre los cuales se encontraban médicos, pedagogos y maestros normalistas que irían conformando un nuevo campo disciplinario y de intervención. La infancia ocupó gran parte de la atención de diferentes actores sociales que se dieron a la tarea de examinar los principales problemas que se enfrentaban en el marco de una nueva redefinición y de una amplia reorganización de las instituciones de asistencia y protección social directamente asociada a la construcción del Estado posrevolucionario mexicano.

Así, a mitad de la década de los años treinta, la visión del Estado mexicano había tenido un giro fundamental: se asociaba estrechamente la beneficencia pública a la asistencia pública y a ésta última se le consideraba como un derecho de las personas. De este modo, la beneficencia pública no era un acto de servicio sino de justicia social. 
Sin duda, tanto el Primer Congreso Criminológico y Penitenciario Mexicano como el Primer Congreso Mexicano del Niño fueron un punto de inflexión acerca del futuro que tendrían los niños y las niñas que estaban entre la orfandad, la protección familiar y la asistencia pública, así como las nuevas o viejas instituciones que tradicionalmente habían sido destinadas a ofrecer casa, vestido, sustento, así como educación, instrucción y capacitación para el trabajo. Al mismo tiempo, se consolidaron o desarrollaron nuevos campos de saber que buscaron intervenir en las estrategias de atención social, especialmente médicos, legistas, psicólogos, pedagogos y maestros, cada uno de ellos buscando legitimar sus saberes, discursos y prácticas científicas e institucionales.

Las amplias y ambiciosas agendas de investigación e intervención son una muestra fehaciente de las preocupaciones que atravesaban a las élites políticas y culturales del país, entre ellos abogados, médicos, criminólogos, antropólogos, filántropos, maestros, sociedades, patronatos, asociaciones de beneficencia privada, todos congregados alrededor del intervencionismo estatal.

Ahora bien, uno de los productos de ese saber fue el diseño de estrategias de intervención psicopedagógica entre cuyos objetivos estaba modificar las anomalías psicológicas, morales y físicas mediante la organización de un engranaje institucional que incorpora instrumentos de medición de la mente y del cuerpo y que se extiende hasta la administración de la vida de los individuos. La adopción de un modelo pedagógico disciplinario resume las ideas de la protección de la infancia. Estas instituciones funcionaron como internados porque esta modalidad garantizaba la vigilancia, la observación y el control de la infancia anormal que, como ya se ha expuso, consideraba a indígenas, campesinos y pobres urbanos.

Aquí únicamente he querido esbozar algunas líneas de interpretación sobre el sentido y significado de la llamada educación correctiva cuya base era la intervención psicopedagógica bajo una orden de ideas, de determinaciones y delimitaciones de poder y saber que convergieron alrededor del campo de la infancia anormal que, por su naturaleza, era compleja y heterogénea por la composición de sus fuerzas diseminadas en prácticas sociales y desplegadas en una red de instituciones, sujetos y discursos con objetivos delimitados pero congregados en torno a fijar o inducir mecanismos de dominación sobre grupos sociales específicos.

Así, el resultado que se esperaba de esas instituciones era que contribuyeran a ordenar las ciudades y el campo, socializando a quienes se consideraba "anormales" tanto mentales como sociales mediante la educación y el trabajo para hacer de ellos ciudadanos civilizados y productivos. En suma, ese saber produjo, entre otras cosas, pedagogías correctivas en la medida en que pretendían prevenir y atender las desviaciones de los sujetos anormales o antisociales. 


\section{Fuentes}

Acevedo Rodrigo, Ariadna (2012), "Las apariencias importan. Indumentaria e higiene personal como marcas de civilización y ciudadanía en la educación para campesinos e indígenas, México, ca. 19211943", en Ariadna Acevedo Rodrigo y Paula López Caballero, (coords.), Ciudadanos inesperados: espacios de formación de la ciudadanía ayer y hoy, México, El Colegio de México-Centro de Investigación y de Estudios Avanzados (Cinvestav).

Aguilar Camín, Héctor y Lorenzo Meyer (2008), A la sombra de la Revolución Mexicana, México, Cal y Arena.

Azaola, Elena (1990), La institución correccional en México: una mirada extraviada, México, Siglo XXICIESAS.

Beteta, Ramón (1931), La mendicidad en México, México, Junta Directiva de la Beneficencia Pública.

Castañeda García, Carmen (1984), Prevención y readaptación social en México (1926-1979), México, Instituto Nacional de Ciencias Penales.

Cruz, Manuel (1921), "Los tribunales para los menores delincuentes. Proyecto del Tribunal Superior del Distrito Federal presentado por el Lic...", en Memoria del Primero Congreso Mexicano del Niño, patrocinado por "El Universal", México, El Universal.

Departamento del Distrito Federal (1929), Reorganización administrativa del Departamento. Acción Educativa, de Reforma, Recreativa y Social del Departamento, México, Talleres Gráficos de la Nación.

Del Castillo Troncoso, Alberto (2006), Conceptos, imágenes y representaciones de la niñez en la Ciudad de México, 1889-1920, México, El Colegio de México-Instituto de Investigaciones Dr. José María Luis Mora.

Gasca, Cecilio, (1923), Informe del Gobierno del Distrito Federal del $1^{\circ}$ de agosto de 1922 al 31 de julio de 1923, México, Tipografía Escuela Correccional.

González Navarro, Moisés (1985), La pobreza en México, México, El Colegio de México.

Lima, Salvador (1929), "Anexo Número 1. Proyecto de Organización y funcionamiento del Patronato de Hogar y de Trabajo del Departamento del Distrito Federal (por) Profr... y Aprobado (por J.M.) Puig (Casauranc)", en Departamento del Distrito Federal, Reorganización administrativa del Departamento. Acción Educativa, de Reforma, Recreativa y Social del Departamento, México, Talleres Gráficos de la Nación.

Loyo Bravo, Engracia (1999), Gobiernos revolucionarios y educación popular en México, 1911-1928, México, Centro de Estudios Históricos/El Colegio de México.

Marcial Avendaño, A. D. (2004), "Higiene y metrópoli en el gobierno de Álvaro Obregón", en María del Carmen Collado (coord.), Miradas recurrentes I. La Ciudad de México en los siglos XIx y XX. México, Instituto de Investigaciones Dr. José María Luis Mora-Universidad Autónoma Metropolitana.

Memoria (1921), Memoria del Primer Congreso Mexicano del Niño patrocinado por "El Universal", México, México, El Universal.

Meyer, Jean (1999), La Revolución Mexicana, México, Jus.

Padilla Arroyo, Antonio, Alcira Soler Durán, Martha Luz Arredondo y Lucía M. Moctezuma (coords.), (2008), La infancia en los siglos xIx y Xx. Discursos e imágenes, espacios y prácticas, México, Universidad Autónoma del Estado de Morelos-Casa Juan Pablos.

Padilla Arroyo, Antonio (2009), "De excluidos e integrados: saberes e ideas en torno a la infancia anormal y la educación especial en México, 1920-1940", Frenia. Revista de Historia de la Psiquiatría, vol. 9, núm. 1, pp. 97-133.

Pedrueza Ramos, Antonio (1921), "Conclusiones formuladas por el Lic...", en Memoria del Primer Congreso Mexicano del Niño patrocinado por "El Universal", México, El Universal. 
Secretaría de Gobernación (1936), Ley Orgánica del Poder Judicial de la Federación, México, Talleres Gráficos de la Nación.

Sandoval de Zarco, María (1921), "Estudio de la Sra. Lic...", en Memoria del Primer Congreso Mexicano del Niño patrocinado por "El Universal", México, El Universal.

Sosenski, Susana (2006), "Diversiones malsanas: el cine y la infancia en la Ciudad de México en la década de 1920", Secuencia. Revista de historia y ciencias sociales, núm. 66, septiembre-diciembre, México, Instituto de Investigaciones Dr. José María Luis Mora.

Stern, Alejandra (2002), "Madres conscientes y niños anormales: la eugenesia y el nacionalismo en el México posrevolucionario, 1920-1940", en Laura Cházaro (ed.), Medicina, ciencia y sociedad en México Siglo xIx, Zamora, Michoacán, El Colegio de Michoacán-Universidad Michoacana de San Nicolás de Hidalgo.

Tiana Ferrer, Alejandro (2005), "La historia de la educación en la actualidad: viejos y nuevos campos de estudio", en Manuel Ferraz Lorenzo (ed.), Repensar la historia de la educación. Nuevos desafíos, nuevas propuestas, Madrid, Biblioteca Nueva.

Urías Horcasitas, Beatriz (2007), Historias secretas del racismo en México, (1920-1950), México, Tusquets Editores.

Vásquez, Josefina Zoraida (2000), Nacionalismo y educación en México, México, El Colegio de México.

Vaughan, Mary Kay (2001), La política cultural en la Revolución. Maestros, campesinos y escuelas en México, 1930-1940, México, Fondo de Cultura Económica.

Velasco Ceballos, Romualdo (1935), El niño mexicano ante la caridad y el estado. Apuntes histórico que comprenden desde la época precortesiana hasta nuestros días, México, Beneficencia Pública en el Distrito Federal.

Yarza, Alexander y Lorena Rodríguez (2007), Educación y pedagogía de la infancia anormal 1870-1940, Bogotá, Cooperativa Editorial Magisterio.

Werner Tobler, Hans (1994), La revolución Mexicana. Transformación social y cambio político, 1876-1940, México, Alianza Editorial.

Antonio Padilla Arroyo. Investigador del Instituto de Ciencias de la Educación, Universidad Autónoma del Estado de Morelos, México. Doctor en Historia por El Colegio de México. Líneas de investigación: Historia de las instituciones educativas e historia de las instituciones de control social, siglos XIX y XX. Historia de la infancia anormal y educación especial, Siglos XIX y XX. Historia social e historia cultural, siglos XIX y XX. Publicaciones recientes: Padilla Arroyo, Antonio (Coord.), (2012), Arquetipos, memorias y narrativas en el espejo. Infancia anormal y educación especial en los siglos XIX y XX. México, Universidad Autónoma del Estado de Morelos/Juan Pablos Editor; Padilla Arroyo, Antonio y Xóchitl Taylor Flores, (2014), "Educación rural en Morelos en la década de 1920", en Inventio. Génesis de la cultura universitaria en Morelos, vol. 9, núm. 19, noviembre 2013-febrero 2014, pp. 19-24; Padilla Arroyo, Antonio y Alcira Soler Durán, (2014), "Descontento, indisciplina y ¿violencia? escolar: discursos y modos educativos en el Instituto Científico y Literario del Estado de México", en Ramírez Martínez, Rosa María y Irma Guadalupe González Corzo, (coords.), 
Estudios sobre violencia en la educación, México, Universidad Autónoma del Estado de México/Universidad Autónoma del Estado de Morelos, pp. 135-167.

Recibido: 15 de mayo de 2014

Aceptado: 20 de octubre de 2014 